\title{
Magnitude of depression problem among primary care consumers in Saudi Arabia
}

\author{
Badria K Al-Dabal, Manal R Koura, Latifa S Al-Sowielem \\ Family \& Community Medicine Department - Medical College, University of Dammam, Dammam, Saudi Arabia. \\ Correspondence to: Badria K Al-Dabal, E-mail: bdabal@ud.edu.sa
}

Received October 20, 2014. Accepted November 22, 2014

Abstract

Background: Depression is one of the leading causes of disability worldwide. It is estimated that $5-10 \%$ of the population at any given time is suffering from identifiable depression needing psychiatric or psychosocial intervention.

Objectives: To determine the prevalence of depression and associated risk factors among adult primary care consumers in Saudi Arabia.

Materials and Methods: A cross-sectional study was conducted in four primary healthcare (PHC) centers in Al Khobar for screening of adult consumers for depression. The data were collected by interviewing a sample of 850 male and female visitors by using the Arabic version of Patient Health Questionnaire 9.

Results: The prevalence of moderate to severe depression among adult PHC consumers was about $16 \%$. Its occurrence was more than double among women than men. The most common manifestations of depression were sleeping and eating problems, while suicidal thoughts were reported by $3.8 \%$ of depressed people. The main predictors of depression were female gender, family history of depression or psychiatric diseases, personal history of chronic diseases, especially cardiovascular and skin diseases, and being unemployed or unmarried; the predictors of suicidal ideation were severe depression, female gender, and low level of education.

Conclusion: We conclude from this study that about one-sixth of PHC consumers in Saudi Arabia are suffering from moderate to severe depression and its occurrence was more in women than men, illiterate, and unemployed.

KEY WORDS: depression, primary healthcare centers, predictors

\section{Introduction}

Depression is a common global mental disorder that affects all aspects of health: physical, mental, and social. It is characterized by sadness, loss of interest, poor concentration, disturbed sleeping, or eating; worsening the health of people with chronic disease at its worst, depression can lead to suicide. Today, depression is estimated to affect 350 million people; the World Mental Health Survey conducted in 17 countries found that, on average, about 1 in 20 people reported having an episode of depression in the previous year, and it is one of the leading causes of disability worldwide. ${ }^{[1]}$ It is projected that, by 2020 , depression will be second only to heart disease in its contribution to the global burden of

\begin{tabular}{|l|l|}
\hline \multicolumn{2}{|c|}{ Access this article online } \\
\hline Website: http://www.jpmsph.com & Quick Response Code: \\
\hline
\end{tabular}

diseases as measured by Disability-Adjusted Life Years. ${ }^{[2]}$ Worldwide, it is estimated that $5-10 \%$ of the population at any given time is suffering from identifiable depression needing psychiatric or psychosocial intervention. The life time risk of developing depression is $10-20 \%$ in women and slightly less in men, and the average age of onset of major depression is between 20 and 40 years. ${ }^{[3]} \mathrm{AL}-$ Khathami reported in his study in primary care in Saudi Arabia that about one-third of primary healthcare $(\mathrm{PHC})$ patients had mental illness. ${ }^{[4]}$ Geriatric depression is widespread affecting at least one of six patients treated in general medical practice in the United States ${ }^{[5]}$; however, depression in the elderly remains underdetected and underdiagnosed, particularly in nonmental health settings. ${ }^{[6]}$

Unfortunately, depression often goes unrecognized in $\mathrm{PHC}$ settings. A number of earlier studies have shown that PHC physicians often overlook depressive disorders and lack the needed skills for recognizing, responding, diagnosing, and treating depressive disorders. ${ }^{[7,8]}$ Although depression can be reliably diagnosed and treated in $\mathrm{PHC}$, less than $25 \%$ (in some countries, fewer than $10 \%$ ) have access to effective treatment. ${ }^{[1,3]}$ The study conducted by Becker revealed that Saudi primary care physicians were aware of psychiatric disorders but their diagnostic skills were poor for somatization and depression. ${ }^{[9]}$ 
The aim of current study is to determine the prevalence of depression and associated risk factors among adult primary care consumers in Al Khobar city, Saudi Arabia.

\section{Materials and Methods}

A cross-sectional study was conducted in four primary health care centers of nine serving Al Khobar city. The centers with the largest population were included in the study. The minimum sample size for estimation of depression prevalence was calculated by Epi-Info for an adult population of 96,000 , at an expected frequency of $17 \pm 3 \%{ }^{[3]}$ and confidence limit of $95 \%$. It was found that the minimum required sample is 599 . Accordingly, a proportionate random sample of 850 adult PHC consumers was selected from the different health centers (about half of the sample were women). They were invited to participate in the study after explaining the purpose of the study and assurance about the confidentiality of collected information. The Arabic version of "Patient Health Questionnaire 9" for screening of depression was utilized. ${ }^{[10,11]}$ The scale consists of nine questions, for which the answers ranged from "not at all" (given a score of 0 ) to "nearly every day" (given a score of 3 ) experiencing the symptom within the last 2 weeks. The total score was calculated and categorized into no depression (0-4), mild depression (5-9), moderate depression
(10-14), and severe depression (15+). Weight and height were also measured for 836 participants (with a response rate of $98.4 \%$ ), and body mass index (BMI) was calculated and categorized into underweight (less than $18.5 \mathrm{~kg} / \mathrm{m}^{2}$ ), normal weight (18.5-24.9), overweight (25-29.9), obesity (30-34.9), and severe obesity (more than $35 \mathrm{~kg} / \mathrm{m}^{2}$ ). Data were verified and entered to statistical package software SPSS. For qualitative statistical analysis, $\chi^{2}$ test was used, and for quantitative analysis, $t$-test and one-way ANOVA with LSD were used. Regression analysis was also conducted, and $P$ value less than 0.05 was considered significant.

\section{Results}

Six hundred and eighty PHC consumers were screened for depression: 430 of them were women and the rest were men. Their mean age was $33.1 \pm 11.3$ years, and the minimum was 19 years and the maximum 80 years.

Figure 1 illustrates the prevalence of depression among PHC consumers in Al Khobar in 2010. It shows that about $16 \%$ had moderate to severe depression, where $11.3 \%$ had moderate depression and $4.8 \%$ had severe depression.

Table 1 demonstrates the distribution of depressive symptoms experienced nearly every day during the last 2 weeks by gender among depressed PHC consumers.

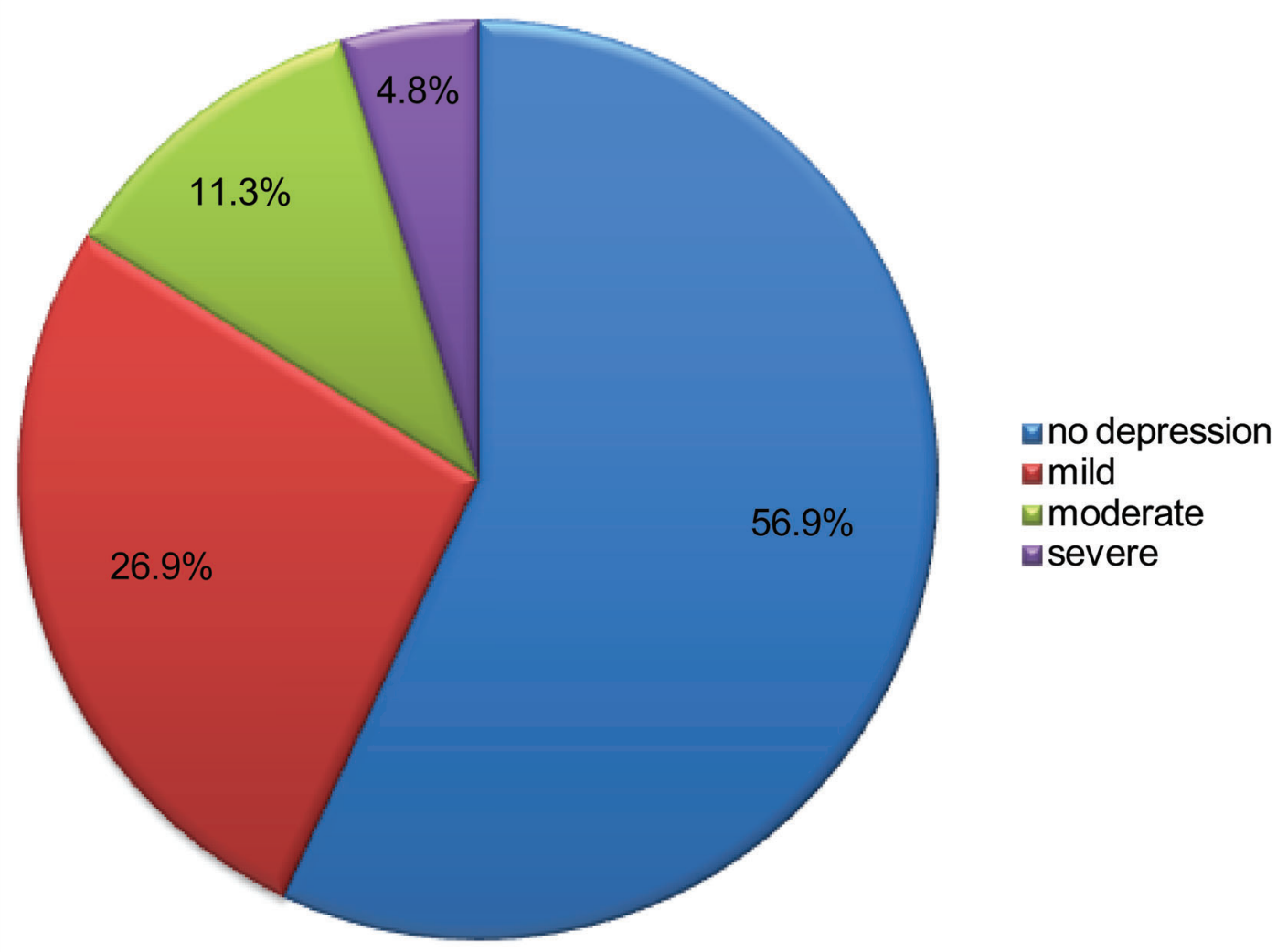

Figure 1: Prevalence of depression among PHC consumers in Al Khobar, 2010. 
Table 1: Distribution of depressive symptoms experienced nearly every day during the last 2 weeks by gender among depressed PHC consumers

\begin{tabular}{|c|c|c|c|c|c|c|c|}
\hline \multirow[t]{2}{*}{ Symptoms } & \multicolumn{2}{|c|}{ Males $(n=145)$} & \multicolumn{2}{|c|}{ Females $(n=221)$} & \multicolumn{2}{|c|}{ Total $(n=366)$} & \multirow{2}{*}{$\begin{array}{c}\chi^{2} \\
\text { P value }\end{array}$} \\
\hline & n & $\%$ & $\mathrm{n}$ & $\%$ & $\mathbf{n}$ & $\%$ & \\
\hline Little interest & 20 & 13.8 & 31 & 14.0 & 51 & 13.9 & 0.43 \\
\hline Hopelessness & 20 & 13.8 & 42 & 19.0 & 62 & 16.9 & 0.001 \\
\hline Sleeping problems & 41 & 28.3 & 63 & 28.5 & 104 & 28.4 & 0.921 \\
\hline Little energy & 21 & 14.5 & 45 & 20.5 & 66 & 18.1 & 0.021 \\
\hline Feeling bad about your self & 13 & 9.0 & 30 & 13.6 & 43 & 11.7 & 0.008 \\
\hline Trouble concentrating & 11 & 7.6 & 33 & 14.9 & 44 & 12.0 & 0.041 \\
\hline Moving or speaking slowly or fidgety & 16 & 11.0 & 21 & 9.5 & 37 & 10.1 & 0.936 \\
\hline Suicidal thoughts & 4 & 2.8 & 10 & 4.5 & 14 & 3.8 & 0.01 \\
\hline
\end{tabular}

It was found that the most common symptom was sleeping problems $(28.4 \%)$, followed by poor appetite or overeating (23\%), little energy (18.1\%), and hopelessness (16.9\%), while suicidal thoughts were reported by $3.8 \%$ of the sample. More than half of the symptoms were significantly more common among women than males, namely hopelessness, self-blaming and guilt feeling, suicidal thoughts, little energy, and poor concentration.

Table 2 shows that the mean depression score of PHC consumers younger than 40 years was significantly higher than that of the older age group. It was also significantly higher among single people than married and among nonworking

Table 2: Mean depression scores of PHC consumers by socioeconomic factors

\begin{tabular}{|c|c|c|c|c|c|c|}
\hline \multirow[t]{2}{*}{ Socioeconomic factor } & \multicolumn{4}{|c|}{ Depression score } & \multirow{2}{*}{$\begin{array}{c}t \text {-test /ANOVA } \\
P \text { value }\end{array}$} & \multirow[t]{2}{*}{ LSD } \\
\hline & $\mathbf{n}$ & $\%$ & Mean & SD & & \\
\hline \multicolumn{7}{|l|}{ Age group } \\
\hline Less than $40 \mathrm{yr}$ & 603 & 71.1 & 5.3 & 4.8 & 0.010 & \\
\hline $40 \mathrm{yr}$ and above & 245 & 28.9 & 4.1 & 4.7 & & \\
\hline \multicolumn{7}{|l|}{ Type of family } \\
\hline Extended & 177 & 20.9 & 5.3 & 4.5 & & \\
\hline \multicolumn{7}{|l|}{ Crowding index } \\
\hline Low & 398 & 47.0 & 4.9 & 4.9 & 0.999 & \\
\hline High & 448 & 53.0 & 4.9 & 4.7 & & \\
\hline \multicolumn{7}{|l|}{ Marital status } \\
\hline Married & 624 & 73.5 & 4.4 & 4.7 & 0.000 & \\
\hline Single & 203 & 23.9 & 6.1 & 4.6 & & 0.000 \\
\hline Widow & 11 & 1.3 & 8.3 & 7.2 & & 0.008 \\
\hline \multicolumn{7}{|l|}{ Education } \\
\hline Illiterate/read and write & 61 & 7.2 & 6.6 & 6.6 & 0.016 & \\
\hline Elementary/middle school & 198 & 23.3 & 5.1 & 5.1 & & 0.030 \\
\hline Secondary school & 339 & 39.9 & 4.9 & 4.4 & & \\
\hline University/postgraduate & 252 & 29.6 & 4.5 & 4.5 & & 0.002 \\
\hline \multicolumn{7}{|l|}{ Employment } \\
\hline Not working & 417 & 49.1 & 5.7 & 5.3 & 0.000 & \\
\hline Working & 360 & 42.4 & 3.8 & 3.9 & & 0.000 \\
\hline Student & 72 & 8.5 & 6.2 & 4.5 & & 0.430 \\
\hline \multicolumn{7}{|l|}{ Monthly income } \\
\hline Low: $<5,000$ SR & 261 & 31.0 & 5.8 & 5.1 & 0.002 & \\
\hline Middle: 5,000-15,000 SR & 453 & 53.7 & 4.6 & 4.7 & & 0.002 \\
\hline High: > 15,000 SR & 129 & 15.3 & 4.4 & 4.6 & & 0.006 \\
\hline
\end{tabular}


people compared with working people. About one-third of the sample came from low income families; the mean depression score was significantly higher among those of low income than among those of middle or high income. It was the highest among illiterate or just reading and writing people, and a significant inverse proportional relationship between educational level and depression score was detected.

Table 3 revealed that the mean depression score was significantly higher among chronically ill patients, especially those suffering from CVD or skin diseases. About $8 \%$ of the sample gave a positive family history of depression; the mean depression score was significantly higher among those having a positive family history of depression or other psychiatric diseases and among people having family problems, especially marital conflicts. When considering body weight, $4.1 \%$ of the sample was underweight; the mean depression score was significantly higher among underweight people compared with overweight or obese people.

All socioeconomic and risk factors were entered in the stepwise logistic regression analysis; it was found that the main predictor of moderate to severe depression among PHC consumers was female gender $(\mathrm{OR}=2.683)$, followed by family history of depression or psychiatric diseases $(O R=1.631)$, history of chronic diseases $(\mathrm{OR}=1.09)$, unemployment $(\mathrm{OR}=0.698)$, and marital status $(\mathrm{OR}=0.455)$ (Table 4).

Table 5 shows the stepwise logistic regression analysis of the factors affecting suicidal ideations among depressed PHC consumers. It was found that the strongest predictor was the severity of depression (OR $=2.8)$, followed by female gender $(\mathrm{OR}=1.9)$ and low educational level $(\mathrm{OR}=0.6)$.

\section{Discussion}

According to this study, about $16 \%$ of adult PHC consumers had moderate to severe depression. The rate was lower than that reported in Riyadh $(18.8 \%)$ and Kuwait $(20.5 \%)^{[12,13]}$ and higher than in Qatar $(13.5 \%, 2010) .{ }^{[14]}$ Similar studies conducted in European countries revealed a prevalence rate ranging from $16.5 \%$ to $22.8 \%,{ }^{[15-17]}$ indicating that the rates in Gulf Region are comparable with those of Europe.

In this study, it was noticed that depression was more common among young, female, uneducated, unemployed, low income, and unmarried people. These findings might be explained by the higher illiteracy and unemployment rates among women in Saudi Arabia compared with men. The illiteracy rate among adult women in 2013 was $8.6 \%$ compared

Table 3: Mean depression scores of PHC consumers by risk factors

\begin{tabular}{|c|c|c|c|c|c|c|}
\hline \multirow[t]{2}{*}{ Risk factors } & \multicolumn{4}{|c|}{ Depression score } & \multirow{2}{*}{$\begin{array}{l}\text { ANOVA } \\
P \text { value }\end{array}$} & \multirow[t]{2}{*}{ LSD } \\
\hline & $\mathbf{n}$ & $\%$ & Mean & SD & & \\
\hline \multicolumn{7}{|l|}{ Chronic diseases } \\
\hline No & 573 & 78.7 & 4.5 & 4.4 & 0.000 & \\
\hline Diabetes & 68 & 9.3 & 3.4 & 3.7 & & 0.042 \\
\hline CVD & 11 & 1.5 & 7.5 & 7.7 & & 0.032 \\
\hline Bronchial asthma & 48 & 6.6 & 5.4 & 3.6 & & 0.174 \\
\hline Skin disease & 25 & 3.4 & 7.4 & 7.2 & & 0.01 \\
\hline Neurological diseases & 3 & 0.4 & 8.0 & 3.0 & & 0.18 \\
\hline \multicolumn{7}{|l|}{ Family history of psychiatric disease } \\
\hline No & 737 & 86.9 & 4.5 & 4.6 & 0.000 & \\
\hline Depression & 70 & 8.3 & 7.3 & 5.2 & & 0.000 \\
\hline Others & 41 & 4.8 & 8.3 & 5.4 & 0.000 & \\
\hline \multicolumn{7}{|l|}{ Family problems } \\
\hline No & 728 & 88.2 & 4.6 & 4.6 & 0.000 & \\
\hline Marital conflicts & 33 & 4 & 7.6 & 6.5 & & 0.000 \\
\hline Domestic violence & 6 & 0.7 & 7.2 & 4.4 & & 0.183 \\
\hline Addiction & 1 & 0.1 & 0 & 0 & & \\
\hline Mentally disabled family member & 8 & 1 & 5.1 & 3.6 & & 0.759 \\
\hline Sensory disabled family member & 7 & 0.8 & 5.6 & 4.4 & & 0.590 \\
\hline Physical disabled family member & 10 & 1.2 & 5.1 & 4.5 & & 0.745 \\
\hline Multiple wives & 32 & 3.9 & 5.9 & 5.1 & & 0.109 \\
\hline \multicolumn{7}{|l|}{ BMI } \\
\hline Underweight: less than 18.5 & 34 & 4.1 & 6.3 & 3.9 & 0.045 & \\
\hline Normal weight: 18.5- & 301 & 36 & 5.4 & 5.2 & & 0.298 \\
\hline Overweight: 25- & 244 & 29.2 & 4.4 & 4.7 & & 0.033 \\
\hline Obesity: 30- & 225 & 26.9 & 4.6 & 4.5 & & 0.049 \\
\hline Severe obesity: $35+$ & 32 & 3.8 & 5.2 & 4.4 & 0.337 & \\
\hline
\end{tabular}


Table 4: Predictors of moderate to severe depression among PHC consumers in Al Khobar

\begin{tabular}{lcccc}
\hline Variables in the equation & $\boldsymbol{P}$ & OR & \multicolumn{2}{c}{$\mathbf{9 5 \%} \mathbf{~ C l}$} \\
\cline { 3 - 5 } & & & Lower & Upper \\
\hline Gender & 0.000 & 2.683 & 1.707 & 4.219 \\
Family history of psychiatric & 0.003 & 1.631 & 1.186 & 2.244 \\
$\quad$ diseases & & & & \\
History of chronic diseases & 0.003 & 1.090 & 1.030 & 1.154 \\
Unemployment & 0.038 & 0.698 & 0.497 & 0.981 \\
Marital status & 0.000 & 0.455 & 0.297 & 0.697 \\
\hline
\end{tabular}

Table 5: Predictors of suicidal ideation among depressed $\mathrm{PHC}$ consumers in Al Khobar

\begin{tabular}{lcccc}
\hline Variables in the equation & $\boldsymbol{P}$ & OR & \multicolumn{2}{c}{$\mathbf{9 5 \%} \mathbf{C I}$} \\
\cline { 3 - 5 } & & & Lower & Upper \\
\hline Depression level & 0.000 & 2.801 & 1.946 & 4.033 \\
Gender & 0.047 & 1.023 & 1.009 & 3.665 \\
Educational level & 0.016 & 0.615 & 0.414 & 0.912 \\
\hline
\end{tabular}

with $3.5 \%$ among men, ${ }^{[18,19]}$ while the unemployment rate among women was $32.1 \%$ compared with $6.1 \%$ among men. ${ }^{[20]}$ The Saudi government recently recognized the magnitude of the problem and created job opportunities for women in many public and private facilities. Hence, the female unemployment rate dropped from 2012 to 2013 by $3.6 \%$.

This study showed that about $3.8 \%$ of depressed patients had suicidal thoughts, which were more common among women. The Eastern Province is the largest province in Saudi Arabia and $\mathrm{Al}$ Khobar is the second largest city with $9 \mathrm{PHC}$ centers serving about 96,000 adult consumers. Accordingly, the estimated number of moderately to severely depressed patients is 15,360 , and those having suicidal ideations reached about 580. Deisenhammer et al. reported that it might take only 10 minutes or less between the suicidal thoughts and actual suicidal attempts in about half of the depressed patients. ${ }^{[21]}$

Patients with moderate depression should be treated with pharmacotherapy or psychotherapy. Combined antidepressants and cognitive behavior therapy may be useful in patients with psychosocial problems, such as marital conflicts, which were found to be associated with depression in our study. In patients with severe depression, pharmacotherapy or combined pharmacotherapy and psychotherapy can be used. ${ }^{[22]}$

Now, the question is "Are we ready to deal with such a burden of disease?" The Ministry of Health established a National Mental Health Committee in 1990 for integrating mental health in primary care. One of its first activities was training of primary care physicians at two progressive levels of skill development. The first level was 1 month of basic training on mental health issues and diagnosis of common mental disorders, aiming to provide at least one trained physician in each primary care center. The second level of training was more intensive and advanced, enabling physicians to identify and treat people with common and severe mental disorders. Importantly, all antidepressants were exempted from the controlled drug list, so that they could be prescribed by primary care physicians. The initiative also established one community mental health center in Al Khobar in 2006; it is served by a psychiatrist, psychiatry resident, social worker, and part-time psychologist. It provides care for referred patients and offers support and supervision to primary care practitioners in that area. ${ }^{[23]}$ So, we are on the right way, but still we have a long way to go.

\section{Conclusion}

We conclude from this study that about one-sixth of PHC consumers in Saudi Arabia are suffering from moderate to severe depression. Its occurrence was more than double among women than men. Suicidal thoughts were reported by $3.8 \%$ of the depressed people. The main predictors of depression were female gender, family history of depression or psychiatric diseases, personal history of chronic diseases, especially cardiovascular diseases and skin diseases, and being unemployed or unmarried; the predictors of suicidal ideation were severe depression, female gender, and low level of education.

\section{References}

1. WHO. Depression Fact Sheet No. 369. Geneva, Switzerland: WHO, 2012. Available at: http://www.who.int/mediacentre/factsheets/fs369/en/ [Accessed].

2. Chapman DP, Perry GS. Depression as a major component of public health for older adults. Prev Chronic Dis. 2008; 5(1):A22.

3. Knandeiwai S. Conquering Depression. New Delhi, India: WHO, 2001.

4. Al-Khathami A. Prevalence of mental illness among Saudi adult primary-care patients in Central Saudi Arabia. Saudi Med J. 2002;23(6):721-4.

5. Reynolds CF III, Kupfer DJ. Depression and aging: a look to the future. Psychiatr Serv. 1999;50(9):1167-72.

6. Steffens DC.A multiplicity of approaches to characterize geriatric depression and its outcomes. Curr Opin Psychiatry. 2009;22(6): 522-6.

7. Gill MJ, Dansky BS. Use of electronic medical records to facilitate screening for depression in primary care. Prim Care Companion J Clin Psychiatry. 2003;5(3):125-9.

8. Gabarrón Hortal E, Vidal Royo JM, Haro Abad JM, Boix Soriano I, Jover Blanca A, Arenas Prat M. [Prevalence and detection of depressive disorders in primary care]. Aten Primaria. 2002;29(6): 329-36.

9. Becker SM. Detection of somatization and depression in primary care in Saudi Arabia. Soc Psychiatry Psychiatr Epidemiol. 2004; 39(12):962-6. 
10. Pfizer, Inc. PHQ-9 Patient Depression Questionnaire. Available at: http://www.integration.samhsa.gov/images/res/PHQ\%20$\% 20$ Questions.pdf [Accessed].

11. Pfizer, Inc. PHQ-9 Patient Depression Questionnaire. Arabic version. Available at: http://www.phqscreeners.com/pdfs/02_PHQ-9/PHQ9_ Arabic\%20for\%20Tunisia.pdf [Accessed].

12. Al-Qadhi W, Ur Rahman S, Farwana MS, Abdulmajeed IA. Adult depression screening in Saudi primary care: prevalence, instrument and cost. BMC Psychiatry. 2014;14(1):190.

13. Al-Otaibi B, Al-Weqayyan A, Taher H, Sarkhou E, Gloom A, Aseeri $\mathrm{F}$, et al. Depressive symptoms among Kuwaiti population attending primary healthcare setting: prevalence and influence of sociodemographic factors. Med Princ Pract. 2007;16(5): 384-8.

14. Bener A, Ghuloum S, Abou-Saleh MT. Prevalence, symptom patterns and comorbidity of anxiety and depressive disorders in primary care in Qatar. Soc Psychiatry Psychaitr Epidemiol. 2012;47(3):349-446.

15. Norton J, de Roquefeuil G, David M, Boulenger JP, Ritchie K, Mann A. Prevalence of psychiatric disorders in French general practice using the patient health questionnaire: comparison with GP case-recognition and psychotropic medication prescription. Encephale. 2009;35(6):560-9.

16. Stromberg $R$, Wernering $E$, Aberg-Wistedt $A$, Furhoff $A$, Johansson S, Backlund L. Screening and diagnosing depression in women visiting GPs' drop in clinic in Primary Health Care. BMC Fam Pract. 2008;9:34-43.

17. Mergl R, Seidscheck I, Allgaier A, Moller H, Hegerl U, Henkel V. Depressive, anxiety and somatoform disorders in primary care: prevalence and recognition. Depress Anxiety. 2007;24(3): 185-95.

18. Central Department of Statistics and Information. Male Population (15 Years and Over) by Age Groups and Educational Status: $1434 \mathrm{H} /$ 2013 G. Available at: www.cdsi.gov.sa [Accessed].

19. Central Department of Statistics and Information. Female Population (15 Years and Over) by Age Groups and Educational Status: 1434 H/ 2013 G. Available at: www.cdsi.gov.sa [Accessed].

20. Central Department of Statistics and Information. Quarterly Unemployment Rates, 2013. Available at: www.cdsi.gov.sa [Accessed June 25, 2014].

21. Deisenhammer EA, Ing CM, Strauss R, Kemmler G, Hinterhuber $H$, Weiss EM. The duration of the suicidal process: how much time is left for intervention between consideration and accomplishment of a suicide attempt? J Clin Psychiatry. 2009;70(1):19-24.

22. Armstrong C. APA releases guideline on treatment of patients with major depressive disorder. Available at: www.aafp.org/afp/ practguide [Accessed].

23. Saudi Ministry of Health. Integrated Primary Care for Mental Health in the Eastern Province. 2010. Available from: http://www.who.int/ mental_health/policy/services/SaudiArabia.pdf [Accessed].

How to cite this article: Al-Dabal BK, Koura MR, Al-Sowielem LS. Magnitude of depression problem among primary care consumers in Saudi Arabia. Int J Med Sci Public Health 2015;4: 205-210

Source of Support: Nil, Conflict of Interest: None declared. 